\title{
PERENCANAAN ANGGARAN PINJAMAN DENGAN PREDIKSI REGRESI LINIER SEDERHANA DAN OPTIMASI MENGGUNAKAN METODE FUZZY TSUKAMOTO
}

\author{
Undang Mustofa ${ }^{1}$, Yessy Yanitasari ${ }^{2}$, Dedih ${ }^{3}$ \\ 1undang.mustofa86@gmail.com, ${ }^{2}$ yessy.yanitasari@gmail.com, ${ }^{3}$ dedihthea@gmail.com \\ 1,2,3 STMIK Kharisma Karawang
}

\begin{abstract}
Abstrak
Dunia usaha sering menghadapi kondisi yang berubah-ubah dalam aktifitas usahanya. Perlu adanya rencana kerja yang tepat agar dunia usaha dapat berkembang, salah satunya perencanaan anggaran. Dalam perencanaan anggaran pinjaman koperasi mengacu pada batasan jumlah pengajuan, belum ada rencana anggaran pinjaman secara nominal sehingga kondisi kas koperasi tidak stabil dan dapat mempengaruhi perkembangan koperasi. Maka dibutuhkan suatu sistem yang dapat memprediksi anggaran pinjaman yang dibutuhkan. Metode yang digunakan dalam penelitian ini yaitu Regresi Linier Sederhana untuk memprediksi anggaran dan Metode Fuzzy Tsukamoto untuk optimasi anggaran. Prediksi anggaran pinjaman bulan April 2019 dengan jumlah modal Rp. 500.000.000 menggunakan prediksi regresi linier sederhana sebesar Rp. 441.690.000, setelah optimasi menggunakan Metode Fuzzy Tsukamoto adalah Rp. 396.960.000 lebih hemat Rp. 44.730 .000 atau 10.12\%.
\end{abstract}

Kata kunci: Anggaran, Regresi Linier, Fuzzy Tsukamoto

\begin{abstract}
The business world often faces changing conditions in its business activities. The right work plan is needed so that the business world can develop, one of which is budget planning. In planning the loan budget in the Cooperative refers to the limit on the number of submissions, there is no nominal loan budget plan so that the cooperative's cash condition is unstable and can affect the development of the cooperative. Then we need a system that can predict the loan budget needed. The method used in this reserch is simple Linear Regression to predict budgets and Tsukamoto Fuzzy Methods for budget optimization. Predicted the loan budget for April 2019 with a total capital of Rp. 500,000,000 using simple linear regression predictions of Rp. 441,690,000, after optimization using the Tsukamoto Fuzzy Method is Rp. $396,960,000$ more savings Rp. $44,730,000$ or $10.12 \%$.
\end{abstract}

Keywords: Budget, Linear Regression, Fuzzy Tsukamoto

\section{Pendahuluan}

Informasi mengenai prediksi anggaran yang dibutuhkan sangat penting dalam perencanaan program kerja organisasi, dengan menggunakan perhitungan regresi linier kumpulan data anggaran yang telah digunakan dapat diolah dan diprediksi untuk perencanaan anggaran selanjutnya [1]. Kondisi yang dihadapi dalam dunia usaha seringkali memiliki ketidakpastian atau kondisi yang berubah-ubah sehingga diperlukan suatu metode untuk memprediksi keadaan yang akan dihadapi. Logika fuzzy merupakan metode dalam menyelesaikan suatu masalah dengan kondisi yang memiliki ketidakpastian. Dalam penerapannya mencakup beberapa bidang, antara lain aplikasi teknik, pengenalan pola, aplikasi media dan aplikasi finansial [2].

Logika fuzzy digunakan sebagai suatu cara untuk memetakan permasalahan dari input menuju ke output [3]. Salah satu penerapan logika fuzzy adalah dalam optimalisasi perencanaan anggaran. Perencanaan anggaran di dalam sebuah organisasi dilakukan untuk dapat mengelola dan mengendalikan operasional organisasi. Anggaran juga berperan bagi manajemen dalam mengontrol pengeluaran [4]. Dalam perencanaan anggaran dipengaruhi oleh beberapa faktor diantaranya rencana kerja, rencana pendapatan, dan rencana belanja.

Semakin berkembangnya kegiatan koperasi di Indonesia maka pengelolaan koperasi dituntut untuk lebih profesional, pengelolaan tersebut memerlukan adanya sistem yang baik dan informasi yang relevan serta dapat diandalkan dalam pengambilan keputusan, perencanaan, maupun pengendalian [5]. Salah satu kegiatan usaha dari koperasi adalah simpan pinjam yang dilakukan untuk menghimpun dana dan menyalurkannya melalui kegiatan usaha simpan pinjam dari dan untuk anggota koperasi yang bersangkutan [6]. 
ILKOM Jurnal Ilmiah Volume 11 Nomor 3 Desember 2019 Terakreditasi peringkat 3 SK. No. 28/E/KPT/2019

Penelitian sebelumnya oleh Ardina[7] mengenai optimasi jumlah pinjaman koperasi menggunakan fuzzy tsukamoto dengan algoritma genetika menghasilkan nilai fitness dari setiap perhitungan yang dioptimasi berdasarkan hasil evaluasi menggunakan perhitungan Mean Absolute Percentage Error. Penelitian berkaitan dengan regresi linier sederhana oleh Iqbal dan Sholihah [8] tentang pengaruh anggaran biaya pemeliharaan aset tetap terhadap realisasi biaya pemeliharaan aset tetap menunjukan pengaruh yang cukup besar antara anggaran biaya pemeliharaan aset tetap terhadap realisasi biaya pemeliharaan aset tetap yaitu sebesar $77,8 \%$. Selanjutnya metode regresi linier sederhana untuk memprediksi pemakaian air bersih PDAM dengan sistem informasi geografis menghasilkan pengujian penyebaran pemakaian air bersih $89 \%$ terpenuhi [9]. Perhitungan metode regresi linier digunakan untuk memprediksi tingkat produksi kopi dimana perhitungan tingkat akurasi menggunakan Mean Square Error (MSE) dan Mean Absolute Percentage Error (MAPE) menghasilkan tingkat akurasi MSE 43,112\% dan MAPE 20,001\% [10].

Penelitian yang berkaitan dengan perencanaan anggaran menggunakan metode fuzzy oleh Nugraha[11] yaitu optimalisasi biaya pelaksanaan konstruksi jalan untuk membuat saluran drainase data input yang diperlukan berdasarkan volume galian drainase yang divariasikan antara volume galian selokan drainase dan saluran air dengan volume pasangan batu mortar menghasilkan total biaya lebih hemat $3.5 \%$. Penerapan perhitungan metode fuzzy sugeno selain dalam perencanaan anggaran dapat diterapkan dalam menentukan harga suatu barang, penelitian oleh Agustin dkk.,[12] dengan menggunakan fuzzy sugeno untuk menentukan harga jual sepeda motor bekas dengan tingkat keakurasian hasil perhitungan dikatakan bagus bila nilainya dibawah $20 \%$, dari 32 sampel motor yang diteliti, setelah didapat harga jual hasil perhitungan fuzzy sugeno kemudian dihitung tingkat keakurasian harga jual antara harga yang ditetapkan oleh dealer dengan harga hasil perhitungan fuzzy sugeno menggunakan MAPE diperoleh nilai sebesar $5.64 \%$.

Penerapan Metode Fuzzy Tsukamoto dalam analisa prediksi jumlah pembuatan roti untuk mengetahui prediksi perencanaan jumlah produksi roti sehingga dapat mengurangi jumlah retur pada beberapa bulan sebelumnya [13]. Perhitungan metode fuzzy diterapkan terhadap hasil pertanian oleh Wibowo dkk., [14] menggunakan fuzzy mamdani untuk diagnosis penyebaran penyakit pada tanaman cabai. Hasil penelitian dalam satu kasus menunjukkan nilai persentase potensi penyebaran penyakit dengan $\mathrm{PH}$ tanah $7.5 \mathrm{pH}$, suhu udara $28^{\circ} \mathrm{C}$, kelembaban udara $75 \mathrm{RH}$ dan penyinaran matahari $35 \%$ adalah $60,25 \%$, sehingga kategori potensi penyebaran penyakit adalah sedang. Hasil tersebut dijadikan dasar menentukan metode pencegahan dan pengendalian untuk menangani suatu penyakit sehingga dapat meningkatkan hasil panen serta petani dapat menghindari kerugian akibat gagal panen. Perhitungan metode fuzzy selanjutnya diterapkan terhadap mendeteksi kerusakan mesin die casting 350 ton dan memprediksi kapan waktu maintenance penggantian untuk mengganti mesin yang rusak dengan fuzzy tsukamoto [15].

Berdasarkan penelitian sebelumnya maka dalam penelitian ini menggunakan regresi linier sederhana untuk memprediksi anggaran untuk pinjaman dan optimasi menggunakan Metode Fuzzy Tsukamoto. Pada Metode Fuzzy Tsukamoto output hasil inferensi dari setiap aturan yang diberikan secara tegas (crisp) berdasarkan a-predikat (fire strength) dan hasil akhirnya diperoleh dengan menggunakan bobot rata-rata [3]. Anggaran untuk pinjaman akan dihitung setiap bulan. Dengan menggunakan prediksi regresi linier sederhana dan Metode Fuzzy Tsukamoto perencanaan anggaran untuk pinjaman dapat dimaksimalkan untuk menentukan target koperasi dalam usaha simpan pinjaman dan menjaga kas koperasi tetap stabil.

\section{Metode}

Alur penelitian menggunakan Prediksi Regresi Linier Sederhana dan Metode Fuzzy Tsukamoto dibagi menjadi 4 tahap, yaitu Tahap A Analisis Data (identifikasi masalah, pengambilan data, dan proses pengelompokan data), Tahap B Prediksi Regresi Linier Sederhana (mencari nilai koeefisien a dan b, menghitung persamaan regresi linier sederhana, hasil perhitungan persamaan regresi linier sederhana), Tahap C Optimasi Metode Fuzzy Tsukamoto (Fuzzifikasi, pembentukan basis pengetahuan, inferensi, defuzifikasi), Tahap D Hasil Optimasi (Hasil optimasi Metode Fuzzy Tsukamoto).

Alur penelitian Prediksi Regresi Linier Sederhana dan Metode Fuzzy Tsukamoto ditunjukkan pada Gambar 1. 
ILKOM Jurnal Ilmiah Volume 11 Nomor 3 Desember 2019

Terakreditasi peringkat 3 SK. No. $28 /$ E/KPT/2019

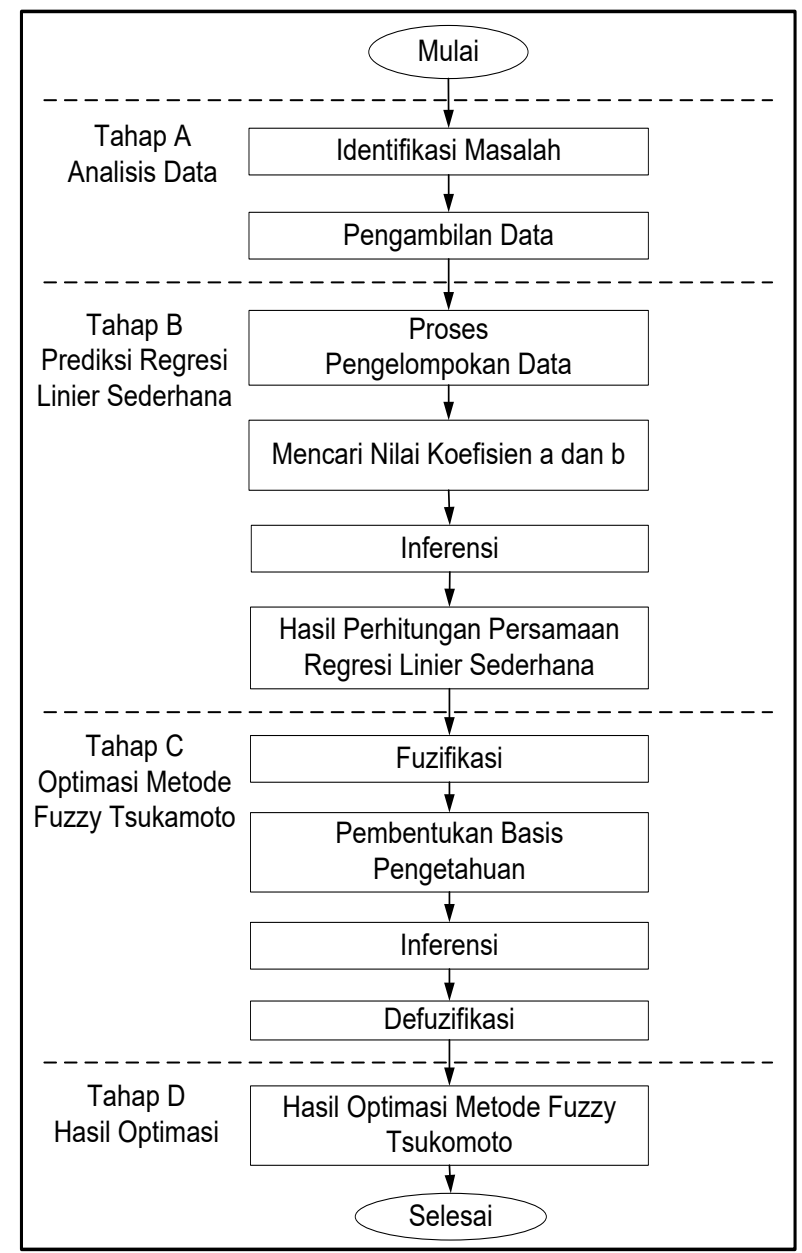

Gambar 1. Alur Prediksi Regresi Linier Sederhana dan Metode Fuzzy Tsukamoto

\section{Hasil dan Pembahasan}

Pada tahapan ini dilakukan analisis terhadap perencanaan anggaran pinjaman dengan prediksi regresi linier sederhana dan optimasi menggunakan Metode Fuzzy Tsukamoto.

\section{Tahap A: Analisis Data}

1. Hasil Identifikasi Masalah

Dalam perencanaan anggaran untuk pinjaman khususnya pinjaman tunai, pengelola koperasi menunggu sampai batas pengajuan akhir bulan sedangkan awal bulan pembukuan dimulai pada tanggal 20 bulan berjalan.

2. Hasil Pengambilan Data

Data yang digunakan adalah data modal dan data realisasi pinjaman dari Januari 2018 sampai Maret 2019 yang ditunjukan pada Tabel 1.

Tabel 1. Hasil Pengambilan Data

\begin{tabular}{llrr}
\hline No & \multicolumn{1}{c}{ Bulan } & $\begin{array}{c}\text { Modal } \\
\text { (dalam satuan juta) }\end{array}$ & $\begin{array}{c}\text { Realisasi Pinjaman } \\
\text { (dalam satuan juta) }\end{array}$ \\
\hline 1 & Januari-2018 & 1.993 & 1.192 \\
2 & Februari-2018 & 1.865 & 1.626 \\
3 & Maret-2018 & 1.684 & 1.684 \\
4 & April-2018 & 1.019 & 954 \\
\hline
\end{tabular}


ILKOM Jurnal IImiah Volume 11 Nomor 3 Desember 2019

Terakreditasi peringkat 3 SK. No. 28/E/KPT/2019

\begin{tabular}{cccc}
\hline No & \multicolumn{1}{c}{ Bulan } & $\begin{array}{c}\text { Modal } \\
\text { (dalam satuan juta) }\end{array}$ & $\begin{array}{c}\text { Realisasi Pinjaman } \\
\text { (dalam satuan juta) }\end{array}$ \\
\hline 5 & Mei-2018 & 583 & 338 \\
6 & Juni-2018 & 789 & 600 \\
7 & Juli-2018 & 476 & 374 \\
8 & Desember-2018 & 598 & 549 \\
9 & Januari-2019 & 465 & 432 \\
10 & Februari-2019 & 558 & 455 \\
11 & Maret-2019 & 656 & 649 \\
\hline
\end{tabular}

3. Hasil Pengelompokan Data

Pengelompokan data diambil dari data modal dan data realisasi pinjaman dari Januari 2018 sampai Maret 2019 dan dilakukan perhitungan, yang ditunjukan pada Tabel 2.

Tabel 2. Hasil Pengelompokan Data

\begin{tabular}{llrrrrr}
\hline No & \multicolumn{1}{c}{ Bulan } & $\begin{array}{c}\text { Modal } \\
(\mathrm{X})\end{array}$ & $\begin{array}{c}\text { Realisasi Pinjaman } \\
(\mathrm{Y})\end{array}$ & \multicolumn{1}{c}{$\mathrm{X.Y}$} & \multicolumn{1}{c}{$\mathrm{X}^{2}$} & $\mathrm{Y}^{2}$ \\
\hline 1 & Januari-2018 & 1.993 & 1.192 & 2375656 & 3972049 & 1420864 \\
2 & Februari-2018 & 1.865 & 1.626 & 3032490 & 3478225 & 2643876 \\
3 & Maret-2018 & 1.684 & 1.684 & 2835856 & 2835856 & 2835856 \\
4 & April-2018 & 1.019 & 954 & 972126 & 1038361 & 910116 \\
5 & Mei-2018 & 583 & 338 & 197054 & 339889 & 114244 \\
6 & Juni-2018 & 789 & 600 & 473400 & 622521 & 360000 \\
7 & Juli-2018 & 476 & 374 & 178024 & 226576 & 139876 \\
8 & Desember- & 598 & 549 & 328302 & 357604 & 301401 \\
9 & Ja18 & 465 & 432 & 200880 & 216225 & 186624 \\
10 & Februari-2019 & 558 & 455 & 253890 & 311364 & 207025 \\
11 & Maret-2019 & 656 & 649 & 425744 & 430336 & 421201 \\
\hline & $\Sigma$ & 10686 & 8853 & 11273422 & 13829006 & 9541083 \\
\hline
\end{tabular}

Tahap B: Prediksi Regresi Linier Sederhana

1. Mencari Nilai Koefisien $a$ dan $b$

a) Mencari nilai a

$$
\begin{aligned}
& a=\frac{\left(\sum Y\right) \cdot\left(\sum X^{2}\right)-\left(\sum X\right) \cdot\left(\sum X Y\right)}{n\left(\sum X^{2}\right)-\left(\sum X\right)^{2}} \\
& a=\frac{(8853) \cdot(13829006)-(10686) \cdot(11273422)}{11(13829006)-(10686)^{2}} \\
& a=\frac{122428190118-120467787492}{152119066-114190596} \\
& a=\frac{1960402626}{37928470} \\
& a=51.69
\end{aligned}
$$


b) Mencari nilai b

$$
\begin{aligned}
& b=\frac{n\left(\sum X Y\right)-\left(\sum X\right) \cdot\left(\sum Y\right)}{n\left(\sum X^{2}\right)-\left(\sum X\right)^{2}} \\
& b=\frac{11(11273422)-(10686) \cdot(8853)}{11(13829006)-(10686)^{2}} \\
& b=\frac{124007642-94603158}{152119066-114190596} \\
& b=\frac{29404484}{37928470} \\
& b=0.78
\end{aligned}
$$

2. Menghitung Persamaan Regresi Linier

Model persamaan regresi linier sederhana yang digunakan adalah :

$$
\hat{Y}=a+b X
$$

Contoh prediksi anggaran pinjaman untuk bulan April 2019 apabila modal yang ada Rp. 500.000.000.

$$
\begin{aligned}
\hat{Y} & =a+b X \\
\hat{Y} & =51.69+(0.78) .500 \\
& =51.69+385 \\
& =441.69 \text { (dalam satuan juta) }
\end{aligned}
$$

Hasil prediksi regresi linier sederhana dari modal adalah Rp. 500.000.000 adalah Rp. 441.690.000.

\section{Tahap C: Optimasi Metode Fuzzy Tsukamoto}

\section{Fuzzifikasi}

Sebagai contoh akan dihitung rencana realisasi pinjaman untuk bulan April 2019 dengan jumlah modal Rp. 500.000.000, prediksi pinjaman bulan April 2019 adalah Rp. 441.690.000. Modal paling tinggi Rp. 1.993.000.000 dan modal paling sedikti Rp. 465.000.000. Prediksi anggaran pinjaman tertinggi Rp. 1.606.000.000 dan terendah Rp. 414.000.000. Realisasi pinjaman tertinggi Rp. 1.684.000.000 dan terendah Rp. 338.000.000. Terdapat 3 variabel fuzzy yaitu modal, prediksi, realisasi. Modal terdiri dari 2 himpunan fuzzy yaitu BANYAK dan SEDIKIT, dengan ketentuan: Modal BANYAK = 1993 dan Modal SEDIKIT = 465. Grafiknya dapat dilihat pada Gambar 2.

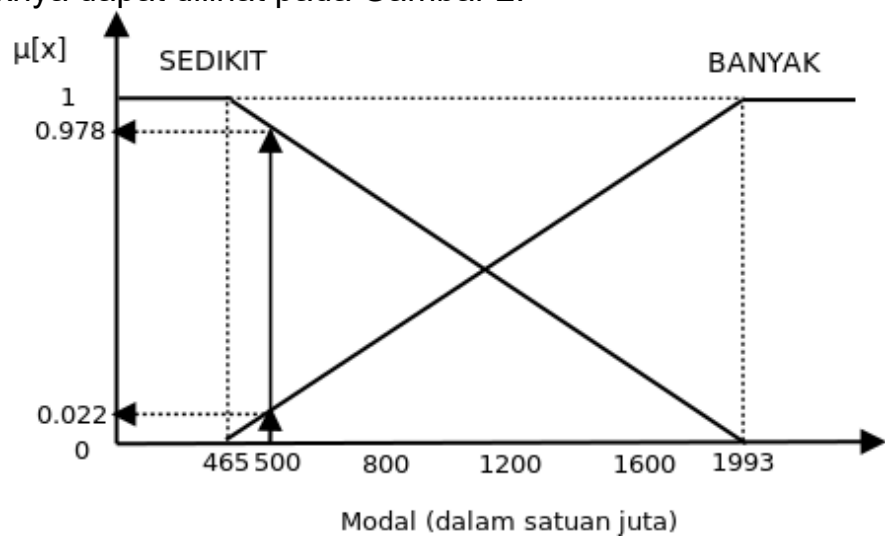

Gambar 2. Grafik fuzzifikasi variabel MODAL 
ILKOM Jurnal Ilmiah Volume 11 Nomor 3 Desember 2019

Terakreditasi peringkat 3 SK. No. 28/E/KPT/2019

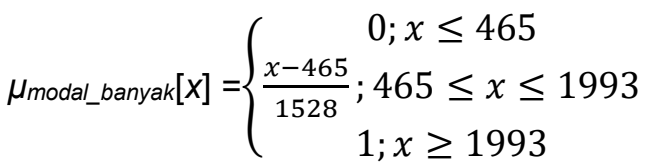

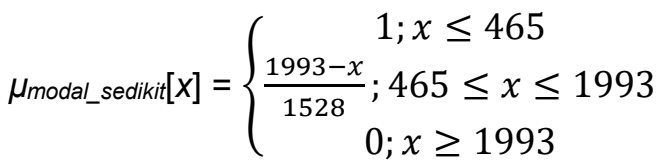

$\mu$ modal_banyak $[500]=(500-465) / 1528=0.022$

$\mu$ modal_sedikit $[500]=(1993-500) / 1528=0.978$

PREDIKSI terdiri dari 2 himpunan fuzzy yaitu TINGGI dan RENDAH. Grafiknya dapat dilihat pada Gambar 3, dengan ketentuan:

Prediksi TINGGI = 1606

Prediksi RENDAH $=414$

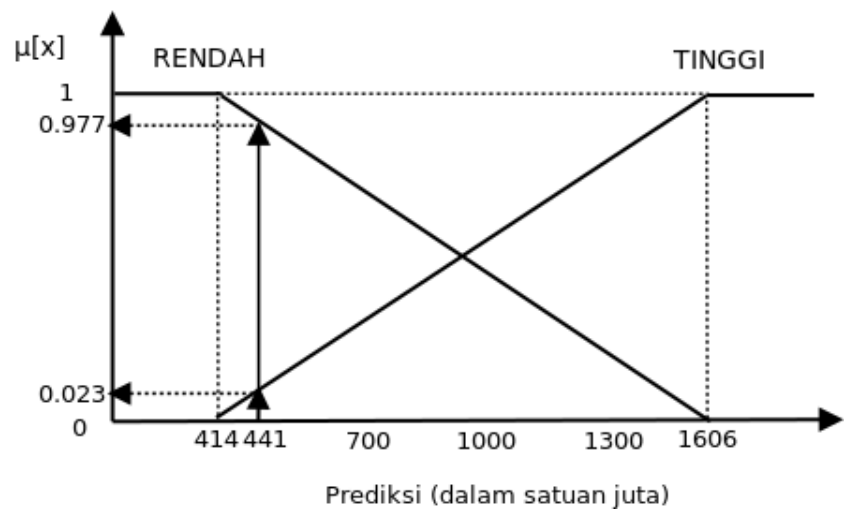

Gambar 3. Grafik fuzzifikasi variabel PREDIKSI

$\mu_{\text {prediksi_tinggi }[y]}=\left\{\begin{array}{c}0 ; y \leq 414 \\ \frac{y-414}{1165} ; 414 \leq y \leq 1606 \\ 1 ; y \geq 1606\end{array}\right.$

$\mu_{\text {prediksi_rendah }[y]}=\left\{\begin{array}{c}1 ; y \leq 414 \\ \frac{1606-y}{1165} ; 414 \leq y \leq 1606 \\ 0 ; y \geq 1606\end{array}\right.$

$\mu$ prediksi_tinggi $[437]=(441-414) / 1165=0.023$

$\mu$ prediksi_rendah[437] $=(1606-441) / 1165=0.977$

REALISASI terdiri dari 2 himpunan fuzzy yaitu TINGGI dan RENDAH. Grafiknya dapat dilihat pada Gambar 4, dengan ketentuan:

Realisasi TINGGI = 1684

Realisasi RENDAH = 338

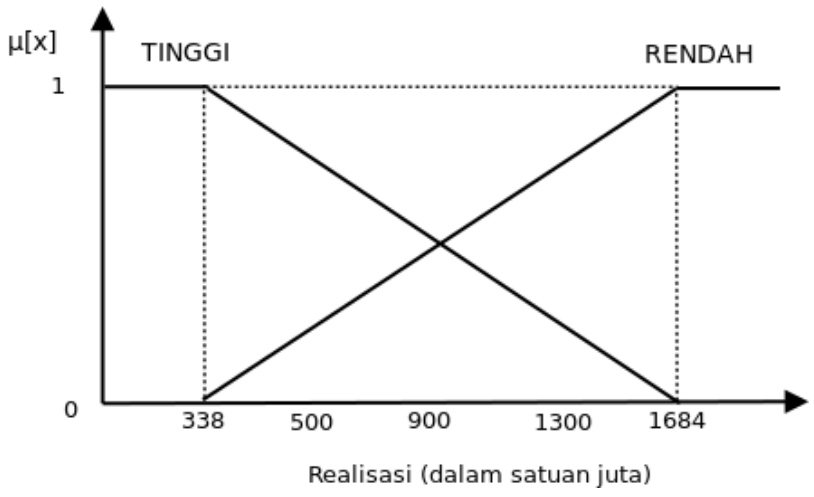

Gambar 4. Grafik fuzzifikasi variabel REALISASI

DOI: https://doi.org/10.33096/ilkom.v11i3.470.206-213 
ILKOM Jurnal Ilmiah Volume 11 Nomor 3 Desember 2019

Terakreditasi peringkat 3 SK. No. 28/E/KPT/2019

2. Pembentukan Basis Pengetahuan Menggunakan 4 aturan fuzzy sebagai berikut:

R1: IF Modal BANYAK AND Prediksi TINGGI THEN Realisai TINGGI

R2: IF Modal BANYAK AND Prediksi RENDAH THEN Realisai TINGGI

R3: IF Modal SEDIKIT AND Prediksi TINGGI THEN Realisasi RENDAH

R4: IF Modal SEDIKIT AND Prediksi RENDAH THEN Realisai RENDAH

3. Inferensi

R1: IF Modal BANYAK AND Prediksi TINGGI THEN Realisasi TINGGI

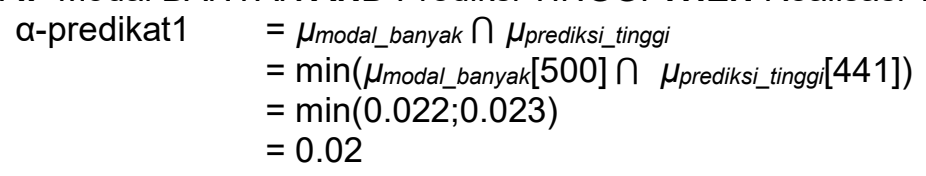

$z 1=(z-338) / 1346=0.022$

$z 1=367.6$

R2: IF Modal BANYAK AND Prediksi RENDAH THEN Realisasi TINGGI

$$
\begin{aligned}
\begin{aligned}
\alpha \text {-predikat2 } & =\mu_{\text {modal_banyak }} \cap \mu_{\text {predeiksi_rendah }} \\
& =\min \left(\mu \text { modal_banyak }[500] \cap \mu_{\text {prediksi_rendah }[441])}\right. \\
& =\min (0.02 ; 0.98) \\
& =0.02
\end{aligned} \\
\begin{aligned}
\mathrm{z} 2=(\mathrm{z}-338) / 1346 & =0.022 \\
\mathrm{z} 2=367.6 &
\end{aligned}
\end{aligned}
$$

R3: IF Modal SEDIKIT AND Prediksi TINGGI THEN Realisasi RENDAH

$$
\begin{aligned}
& \alpha \text {-predikat3 }=\mu_{\text {modal_sedikit }} \cap \mu_{\text {prediksi_tinggi }} \\
& =\min \left(\mu_{\text {modal_sedikit }}[500] \cap \mu_{\text {prediks__tinggi[ }}[441]\right) \\
& =\min (0.978 ; 0.023) \\
& =0.023 \\
& z 3=(1684-z) / 1346=0.023 \\
& z 3=1653
\end{aligned}
$$

R4: IF Modal SEDIKIT AND Prediksi RENDAH THEN Realisasi RENDAH

$$
\begin{aligned}
\text { a-predikat4 } & =\mu_{\text {modal_sedikit }} \cap \mu_{\text {prediksi_rendah }} \\
& =\min \left(\mu_{\text {modal_sedikit }}[500] \cap \mu_{\text {prediksi_rendah[ }}[441]\right) \\
& =\min (0.978 ; 0.977) \\
& =0.98
\end{aligned}
$$

4. Defuzzifikasi

$$
\begin{aligned}
Z & =\frac{\sum_{i=1}^{n} \propto i Z i}{\sum_{i=1}^{n} \propto i} \\
Z & =\frac{414}{1.044} \\
Z & =396.96
\end{aligned}
$$

Hasil defuzzifikasi adalah 396.96 (dalam satuan juta).

\section{Tahap D : Hasil Optimasi}

Berdasarkan hasil prediksi menggunakan regresi linier sederhana sebesar Rp. 441.690.000, setelah optimasi menggunakan Metode Fuzzy Tsukamoto didapatkan nilai optimasi Rp. 396.960.000. nilai tersebut menunjukkan selisih yang lebih hemat sebesar Rp. 44.730 .000 atau $10.12 \%$. 
ILKOM Jurnal Ilmiah Volume 11 Nomor 3 Desember 2019 Terakreditasi peringkat 3 SK. No. 28/E/KPT/2019

\section{Kesimpulan dan Saran}

Berdasarkan penelitian yang telah dilakukan maka dapat ditarik kesimpulan sebagai berikut: Anggaran pinjaman bulan April 2019 dengan jumlah modal Rp. 500.000.000 menggunakan prediksi regresi linier sederhana sebesar Rp. 441.690.000, setelah optimasi menggunakan Metode Fuzzy Tsukamoto adalah Rp. 396.960 .000 lebih hemat Rp. 44.730 .000 atau $10.12 \%$ dengan batas maksimal jumlah anggaran yang bisa dioptimasi adalah Rp. 535.000.000. Namun penelitian ini perlu dilakukanperbaikan dengan menerapkan meode Fuzzy yang lainnya.

\section{Daftar Pustaka}

[1] Sudjana, "Metoda Statistika", Bandung, ISBN: 979-9185-37-8, 2005.

[2] A. R. Wardani., Y. N. Nasution., F. D. T. Amijaya, "Aplikasi Logika Fuzzy Dalam Mengoptimalkan Produksi Minyak Kelapa Sawit di PT. Waru Kaltim Plantation Menggunakan Metode Mamdani", Jurnal Informatika Mulawarman, Vol. 12, No. 2, e-ISSN 2597-4963, p-ISSN 1858-4853, Sept. 2017.

[3] Kusumadewi Sri, Purnomo, Hari, "Aplikasi Logika Fuzzy Untuk Pendukung Keputusan", Andi Yogyakarta, ISBN: 978-979-756-632-6, 2013.

[4] K. R. Anwar., T. Listyorini, "Rancang Bangun Aplikasi E-Budgeting Untuk Mengontrol Anggaran Pendapatan dan Belanja Universitas Muria Kudus", Jurnal Simetris, Vol. 9, No. 2, p-ISSN 22524953, e-ISSN 2549-3108, Nov. 2018.

[5] M. Irwadi, "Analisis Anggaran Kas Sebagai Alat Perencanaan dan Pengendalian Pada Koperasi KOPDIT Rukun Palembang”, Jurnal ACSY, Vol. III, No. 2, ISSN 2407-2184, Jul-Des. 2015.

[6] PP No.9, "Peraturan Pemerintah Republik Indonesia Nomor 9 Tahun 1995. Tentang Pelaksanaan Kegiatan Usaha Simpan Pinjam Oleh Koperasi”, 1995.

[7] S. P. Ardina., I. Cholissodin., B. D. Setiawan, "Optimasi Jumlah Pinjaman Koperasi Menggunakan Fuzzy Tsukamoto dengan Algoritme Genetika", Jurnal Pengembangan Teknologi Informasi dan IImu Komputer, Vol. 2, No. 3, e-ISSN. 2548-964X, Maret, 2018. [Online].

[8] M. Iqbal., G. Sholihah, "Pengaruh Anggaran Biaya Pemeliharaan Aset Tetap Terhadap Realisasi Biaya Pemeliharaan Aset Tetap", Jurnal Akurat IImiah Akuntansi, Vol. 7, No. 2, ISSN. 2086-4159. pp. 27-43, Mei-Agust. 2016.

[9] A. Hijriani., K. Muludi., E. A. Andini, "Implementasi Metode Regresi Linier Sederhana pada Penyajia Hasil Prediksi Pemakaian Air Bersih PDAM WAY Rilau Kota Bandar Lampung dengan Sistem Informasi Geofgrafis", Jurnal Informatika Mulawarman, Vol. 11, No. 2, ISSN. 1858-4853, September 2016.

[10] P. Katemba., R. K. Djoh, "Prediksi Tingkat Produksi Kopi Menggunakan Regresi Linear", Jurnal IImiah Flash, Vol. 3, No. 1, Juni 2017.

[11] F. Nugraha., A. Pujiraharjo., R. Anwar, "Optimalisasi Biaya Pelaksanaan Konstruksi Jalan dengan Metode Logika Fuzzy FIS Takagi-Sugeno Pada Proyek Jalan Trans Kalimantan Provinsi Kalimantan Utara", Jurnal Rekayasa Sipil, Vol.12, No. 1, ISSN. 1978 - 5658, 2018.

[12] A. H. Agustin., G. K. Gandhiadi., T. B. Oka, "Penerapan Metode Fuzzy Sugeno Untuk Menetukan Harga Jual Sepeda Motor Bekas", E-Jurnal Matematika, Vol. 5, No. 4, ISSN. 2303-1751, Nov. 2016.

[13] M. Munawaroh, "Analisa Prediksi Jumlah Pembuatan Roti Menggunakan Penerapan Metode Fuzzy Inference System dengan Algoritma Tsukamoto", Jurnal Pengembangan IT, Vol. 03, No. 02, ISSN. 2477-5126, e-ISSN 2548-9356, Mei. 2018. [Online].

[14] D. S. Wibowo, Y. Yanitasari, D. Dedih, "Sistem Pakar Diagnosis Penyakit pada Tanaman Cabai Menggunakan Fuzzy Mamdani", Jurnal Teknologi dan Sistem Komputer, Vol. 6, No. 2, doi: 10.14710/jtsiskom.6.2.2018.71-75, Apr. 2018. [Online].

[15] K. Karyanto., A. B. Purba., Y. Yanitasari. "Sistem Pakar Mendiagnosis Kerusakan Mesin Die Casting 350 Ton dengan Metode Fuzy Logic Berbasis Web". Jurnal Interkom, Vol. 12, No.4, Januari. 2018. 